\title{
Model Pemangku Kepentingan dalam Keberhasilan Proyek
}

\author{
Herry Pintardi Chandraํ, Indarto ${ }^{1}$, I Putu Artama Wiguna ${ }^{1}$, Peter F. Kaming ${ }^{2}$
}

\begin{abstract}
Stakeholder condition is particularly important to reach project success. The objective of this study is to investigate the stakeholder conditions which are suggested in three parts; stakeholder impact, stakeholder engagement, and stakeholder psychological empowerment on project success. The data obtained from a questionnaire survey administered to 197 respondents for initial research, 204 for main research, and 5 construction companies for validation research by using structural equation modeling (SEM) with program AMOS 16. The results indicated that stakeholder psychological empowerment applying of the ability to perform has a significant influence on project success measured by quality performance. On the other hand, stakeholder engagement reflected by engagement scope has no significant influence on project success.
\end{abstract}

Keywords: Stakeholder impact, stakeholder engagement, stakeholder psycho-logical empowerment, and project success.

\section{Pendahuluan}

Pemangku kepentingan merupakan kelompok atau individu yang memengaruhi atau dipengaruhi oleh pencapaian tujuan organisasi, mempunyai pengaruh dalam memberikan masukan, dan memperoleh manfaat dari keluaran yang dihasilkan (Ward dan Chapman [17]). Proyek adalah suatu usaha yang bersifat temporer untuk menciptakan produk, layanan, atau keluaran yang bersifat unik dengan melibatkan pemangku kepentingan dengan perbedaan lokasi, disain, keadaan, kontraktor, pemilik, atau pemangku kepentingan yang ada (Project Management Institute [13]). Keberhasilan proyek diukur oleh kinerja biaya, waktu, kualitas, laba, dan kepuasan konsumen (Ling et al.[10)], Project Management Institute [13]).

Pertimbangan terhadap dampak yang disebabkan oleh pemangku kepentingan, pengikatan pemangku kepentingan, dan keberdayaan psikologis pemangku kepentingan, akan memberi manajer proyek manfaat dalam mencapai keberhasilan proyek. Manajer proyek perlu mempertimbangkan kebutuhan dan persyaratan yang dikehendaki oleh pemangku kepentingan (Aaltonen et al. [1]), dan memperhatikan pengikatan pemangku kepentingan (Chinyio dan Akintoye [6]) untuk mencapai keberhasilan proyek.

Rumitnya pengelolaan pemangku kepentingan seringkali menimbulkan konflik, dan pemangku ke-

\footnotetext{
1 Fakultas Teknik Sipil dan Perencanaan, Jurusan Teknik Sipil, Institut Teknologi Sepuluh Nopember Surabaya, Kampus ITS Keputih Sukolilo 60111. Email: herrypintardi@gmail.com, indarto@ce.its.ac.id

${ }_{2}^{2}$ Fakultas Teknik Sipil dan Perencanaa, Jurusan Teknik Sipil, Universitas Atma Jaya Yogyakarta, Л. Babarsari 44, Yogyakarta 55281. Email: kaming@mail.uajy.ac.id.
}

Diterima 25 April 2011; revisi 16 Mei 2011; revisi2 21 Mei 2011 diterima untuk dipublikasikan 27 Mei 2011. pentingan bisa tidak memberikan dukungan secara langsung maupun tidak langsung terhadap keberhasilan proyek (Aaltonen et al. [1]). Pemangku kepentingan merupakan sumber ketidakpastian yang mempunyai kepentingan yang menonjol dan motivasinya dapat mempengaruhi aktifitas proyek. Oleh karena itu manajer proyek tidak dengan mudah dapat mengelola pemangku kepentingan, karena pemangku kepentingan juga mempunyai kekuatan, legitimasi, tingkat urgensi (Mitchell et al., dalam Ward dan Chapman [17]).

Walaupun demikian, manajer proyek perlu mengelola interaksi antar pemangku kepentingan untuk mempertemukan pemilik, sponsor, pelanggan, atau pemangku kepentingan yang terkait; memenuhi kepentingan dan harapan pemangku kepentingan; dan bersaing dalam melayani permintaan konsumen sesuai dengan kinerja biaya, waktu, kualitas, laba, dan kepuasan konsumen. Hal ini dapat dilakukan dengan membuat visualisasi pemangku kepentingan yang selanjutnya dapat dipakai untuk mengembangkan strategi pengikatan pemangku kepentingan (Walker et al. [18). Seorang manajer proyek dapat memaksimalkan peran positif dan meminimalkan dampak negatif yang ditimbulkan pemangku kepentingan, bila pemangku kepentingan tersebut dapat diidentifikasikan terlebih dahulu. Konsep pengikatan dan keberdayaan pemangku kepentingan merupakan pendekatan manajemen dalam mengeneralisasikan keberdayaan pemangku kepentingan untuk menghasilkan kepuasan proyek (Rowlinson dan Cheung [14]). Mengetahui informasi tentang kemampuan setiap pemangku kepentingan juga merupakan hal penting, karena melaluinya seorang manajer proyek dapat membuat prediksi perilaku pemangku kepentingan dimana perilaku tersebut dapat memengaruhi keluaran proyek (Cleland [7]). Tantangan jasa konstruksi ke depan 
tidak cukup hanya dihadapi pelaku jasa konstruksi saja, tetapi seyogyanya melibatkan pemangku kepentingan.

Melihat fenomena di atas, permasalahan yang perlu dipecahkan adalah bagaimana mengetahui pengaruh kondisi pemangku kepentingan dalam keberhasilan proyek. Untuk menjawab permasalahan tersebut, maka perlu mengkaji dampak pemangku kepentingan, pengikatan pemangku kepentingan, dan keberdayaan psikologis pemangku kepentingan agar keberhasilan proyek dapat dicapai. Model kondisi pemangku kepentingan dalam keberhasilan proyek diharapkan dapat dipakai untuk membuat prediksi dan peringatan dini terhadap hal-hal yang bisa ditimbulkan oleh pemangku kepentingan.

\section{Metode Penelitian}

Penelitian ini adalah penelitian yang bersifat eksplanasi yang menjelaskan hubungan sebab akibat antara variabel independen dengan variabel dependen yang dilakukan dengan pengujian hipotesis. Pendekatan penelitian ini adalah penelitian kuantitatif dengan sumber data yang berasal dari kuesioner dimana penekanannya pada hasil dan interpretasi dari model empiris yang pengukurannya berdasarkan kajian teoritis.

Penelitian ini diawali dengan penelitian pendahuluan terhadap 197 responden dari kalangan pelaku jasa konstruksi dan pakar perguruan tinggi yang bertujuan untuk mengetahui seberapa penting faktor yang mempengaruhi pemangku kepentingan dalam keberhasilan proyek. Berikutnya adalah penelitian utama dengan melibatkan 204 responden pelaku jasa konstruksi (pemilik bangunan, konsultan manajemen konstruksi, konsultan perencana, kontraktor, dan subkontraktor/pemasok) di Jawa Timur yang bertujuan untuk menilai seberapa baik faktor tersebut pada masing-masing responden. Bagian terakhir adalah validasi penelitian yang melibatkan lima perusahaan kontraktor. Kesinambungan hubungan antara penelitian pendahuluan, penelitian utama, dan validasi penelitian utama adalah untuk mengetahui konsistensi model yang didapat, dan sejauh mana perbedaan hasil predikisi keberhasilan proyek dengan menggunakan model tersebut dapat diketahui.

Untuk menjawab permasalahan yang ada dalam penilitian ini, maka disusun tiga buah hipotesis berdasarkan kajian teoritis . Ketiga hipotesis itu adalah:

Hipotesis 1: Manajer proyek yang mempunyai komitmen terhadap dampak pemangku kepentingan akan berpengaruh signifikan terhadap keberhasilan proyek. Suksesnya pengelolaan pemangku kepentingan dalam mencapai keberhasilan proyek didasarkan pada perhitungan dampak potensial terhadap pemangku kepentingan selama siklus proyek (Cleland [7]).

Variabel dampak pemangku kepentingan didasarkan pada ekses yang disebabkan dampak tersebut sehingga bisa mempengaruhi keberhasilan proyek (Nguyen et al. [12]). Dampak yang ditimbulkan pemangku kepentingan terhadap suksesnya proyek disebabkan karena kekuasaan, legitimasi, urgensi, kedekatan, kepentingan pribadi, sikap, dan pengetahuan yang dimiliki pemangku kepentingan (Nguyen et al. [12]). Hal yang senada juga diungkapkan oleh Ward dan Chapman [17], dimana ketidakpastian yang ditimbulkan oleh pemangku kepentingan salah satunya ditentukan oleh klasifikasi pemangku kepentingan (posisi, kekuasaan, isu, dan kepentingan pribadi). Untuk mengidentifikasi dan menilai dampak pemangku kepentingan, tim proyek harus mempertimbangkan bagaimana kewenangan yang dimiliki pemangku kepentingan akan memengaruhi atau dipengaruhi dalam mencapai tujuan proyek (Cleland [7D. Dampak pemangku kepentingan yang ditimbulkannya sehubungan dengan kekuatan, legitimasi, urgensi (Mitchell et al. dalam Ward dan Chapman [17]), kedekatan, pengetahuan, kepentingan pribadi, dan sikap (Bourne, McElroy dan Mills, Mallak dalam Nguyen et al. [12]).

Hipotesis 2: Manajer proyek yang mempunyai komitmen terhadap pengikatan pemangku kepentingan akan berpengaruh signifikan terhadap keberhasilan proyek. Pemangku kepentingan merupakan sesuatu yang tidak kelihatan yang mengikat tim proyek, dan bekerja sama untuk mendukung keberhasilan proyek (Li dan Walker dalam Rowlinson dan Cheung [14]).

Pengikatan pemangku kepentingan adalah pengembangan dan kesinambungan hubungan antara pemangku kepentingan dalam proyek (Lerbinger [9]). Pengikatan pemangku kepentingan dilakukan dengan pendekatan karyawan, konsumen, lingkup, dan proses (Ayuso et al. [5]). Chinyio dan Akintoye [6] merekomendasikan bahwa pengikatan pemangku kepentingan dapat dilakukan dengan pendekatan manajerial dan pendekatan operasional. Pengikatan karyawan direalisasikan dengan membentuk kebijakan dalam penghentian karyawan, adanya mekanisme resolusi jika terjadi keluhan, pelatihan, dan sistem rekrutmen karyawan. Perusahaan diharapkan dapat lebih mengikat dan membuat hubungan antara perusahaan dan karyawan lebih harmonis dengan membuat kebijakan seperti itu. Pengikatan konsumen merefleksikan adanya saluran umpan balik yang menampung perbedaan, tersedianya basis data, tersedianya meja bantu 
informasi, yang semuanya bertujuan agar terjadi komitmen dengan pelanggan. Lingkup pengikatan dilihat berdasarkan jumlah pemangku kepentingan yang membuat kerja sama atau kontrak dengan perusahaan. Proses pengikatan diukur dari perbedaan mekanisme pengikatan dengan mengidentifikasi, melakukan pertemuan, umpan balik, dan kemitraan jangka panjang dengan pemangku kepentingan. (Ayuso et al. [5]). Barret dan Stanley dalam Chinyio dan Akintoye [6] menunjukkan bahwa proses pengikatan dalam proyek konstruksi terutama selama briefing dapat dilakukan dengan pemberdayaan klien, mengelola dinamika proyek, melibatkan pengguna, menggunakan teknik visualisasi, dan membangun tim.

Hipotesis 3: Manajer proyek yang mempunyai komitmen terhadap keberdayaan psikologis pemangku kepentingan akan berpengaruh signifikan terhadap keberhasilan proyek. Model keberdayaan psikologis mempunyai hubungan positip terhadap perilaku kinerja, dan menumbuhkan nilai bagi organisasi untuk memperbaiki kinerja proyek (Tuuli dan Rowlinson [16]).

Ahadzie et al. [3] menjelaskan bahwa untuk mencapai kinerja keluaran, diperlukan kinerja perilaku tugas (kemampuan kognitif, pengetahuan kerja, kecakapan tugas, pengalaman), dan perilaku kinerja kontekstual (dedikasi pekerjaan dan fasilitas antar personal). Secara umum keberdayaan psikologis pemangku kepentingan ditinjau berdasar 5 hal yaitu motivasi intrinsik, peluang tampil, kemampuan tampil, perilaku kinerja tugas, dan perilaku kinerja kontekstual (Tuuli dan Rowlinson [16]). Motivasi intrinsik diukur terhadap seberapa baik perasaan seseorang terhadap dirinya dan pekerjaannya. Keberdayaan psikologis mempunyai hubungan positif dengan motivasi intrinsik, dimana motivasi intrinsik ditunjukkan oleh opini yang akan berjalan baik jika seseorang mengerjakan pekerjaannya dengan baik (Hackman dan Oldham dalam Tuuli dan Rowlinson, [16]). Peluang tampil diukur dengan seberapa sering peluang itu sulit atau tidak memungkinkan untuk ditampilkan atau dilaksanakan pada pekerjaan (Spector dan Jex dalam Tuuli dan Rowlinson[16]). Kemampuan tampil diukur dari pengalaman, pelatihan, pengetahuan kerja, yang memungkinkan seseorang mempunyai kemampuan untuk melaksanakan pekerjaannya (Podsakoff et al. dalam Tuuli dan Rowlinson [16]). Perilaku kinerja tugas mencerminkan bagaimana seseorang melakukan pekerjaannya yang diukur dari kelayakan dalam melengkapi tugas yang dibebankan, tanggung jawab sesuai dengan uraian pekerjaan, melaksanakan tugas yang diharapkan (Williams dan Anderson dalam Tuuli dan Rowlinson [16]).
Untuk mencapai keberhasilan proyek dapat dilakukan dengan mengembangkan hard project skills yang fokus pada waktu, biaya, dan kualitas; serta mengembangkan soft people engagement skills yang fokus pada identifikasi pemangku kepentingan, manajemen dan pengikatan pemangku kepentingan. Memperbaiki pengikatan pemangku kepentingan dapat membantu mengelola harapan pemangku kepentingan, mengurangi risiko yang tak terduga, atau mengurangi tindakan negatif yang berdampak potensial pada penurunan keberhasilan proyek (Atkin dan Skitmore [4]). Ling et al. ([10]) mengukur kinerja proyek dari kinerja biaya, kinerja waktu, kinerja kualitas, kepuasan konsumen, kinerja laba, dan kepuasan publik. Toor dan Ogunlana [15] menggali indikator kinerja kunci keberhasilan proyek dari perspektif waktu, biaya, keamanan, kesesuaian spesifikasi, efisiensi, efektifitas, bebas cacat, sesuai harapan pemangku kepentingan, minimalisasi keberatan, perselisihan dan konflik.

\section{Hasil dan Pembahasan}

\section{Penelitian Pendahuluan}

Penelitian pendahuluan berfungsi sebagai pilot penelitian untuk mendapatkan model awal berdasarkan evolusi pemodelan referensi peneliti sebelumnya. Dari penelitian pendahuluan ini diketahui signifikansi tingkat kepentingan setiap variabel indikator terhadap variabel latennya. Model penelitian pendahuluan ini ditindak lanjuti pada penelitian utama.

Penelitian pendahuluan dilakukan terhadap 197 responden yang terdiri dari 43 responden mewakili pemilik bangunan, 12 responden mewakili konsultan manajemen konstruksi, 27 responden mewakili konsultan perencana, 93 responden mewakili kontraktor, 20 responden mewakili subkontraktor/ pemasok, dan 2 responden mewakili pakar/perguruan tinggi. Model persamaam struktural dalam penelitian pendahuluan mempunyai variabel laten eksogen dampak pemangku kepentingan (stakeholder impact), pengikatan pemangku kepentingan (stakeholder engagement), dan keberdayaan psikologis pemangku kepentingan (stakeholder psychological empowerment); dan variabel laten endogen keberhasilan proyek (project success). Setelah melalui proses perhitungan dengan analisis structural equation modeling (SEM) dengan program AMOS 16, dari 21 variabel indikator akhirnya didapat 17 variabel indikator yang signifikan. Ketujuh belas variabel indikator tersebut tertera pada Tabel 1 dan model penelitian pendahuluan seperti pada Gambar 1. 


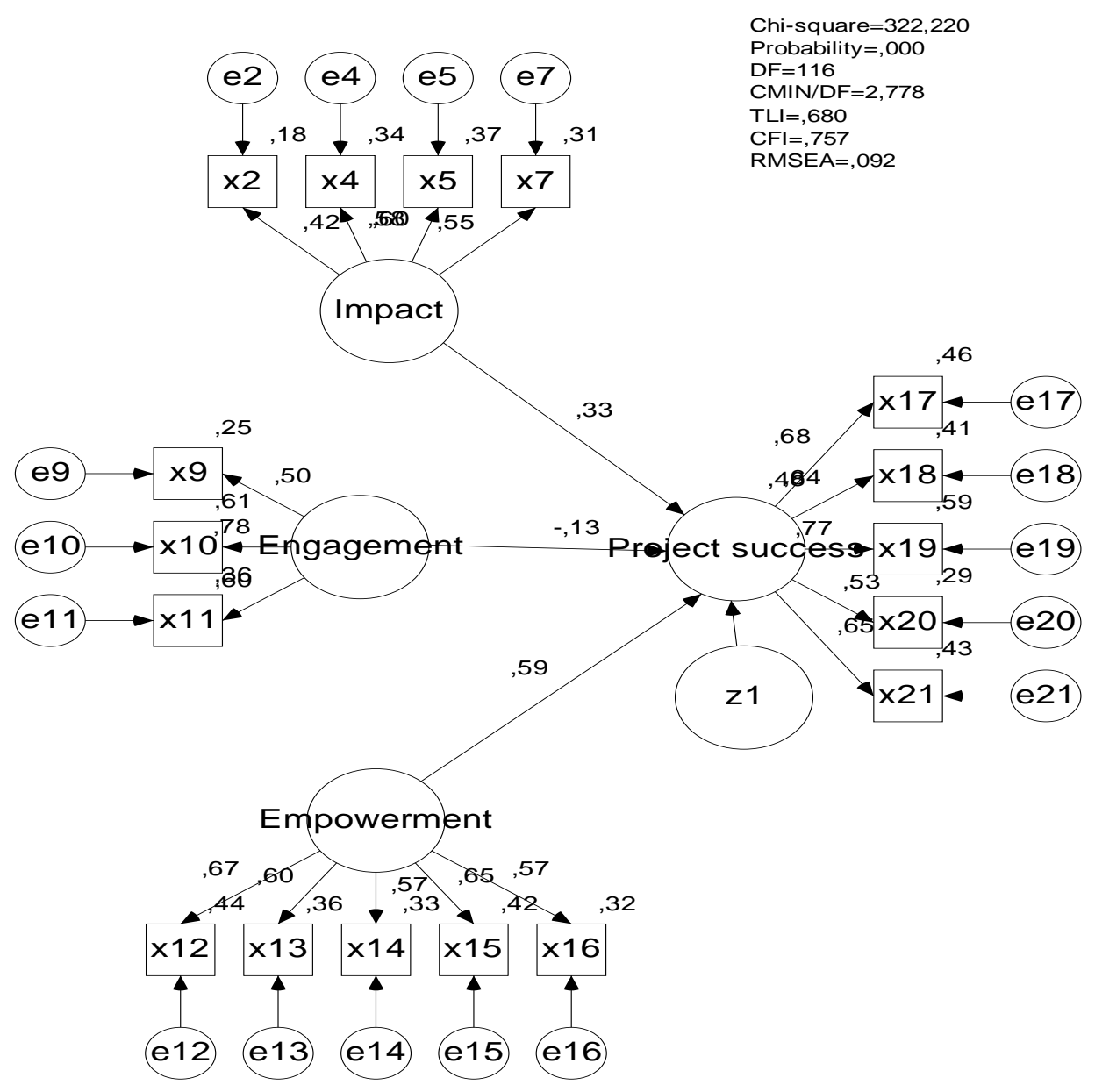

Final SEM (17 variables)

Gambar 1. Model penelitian Pendahuluan

Tabel 1. Indikator untuk setiap variable penelitian

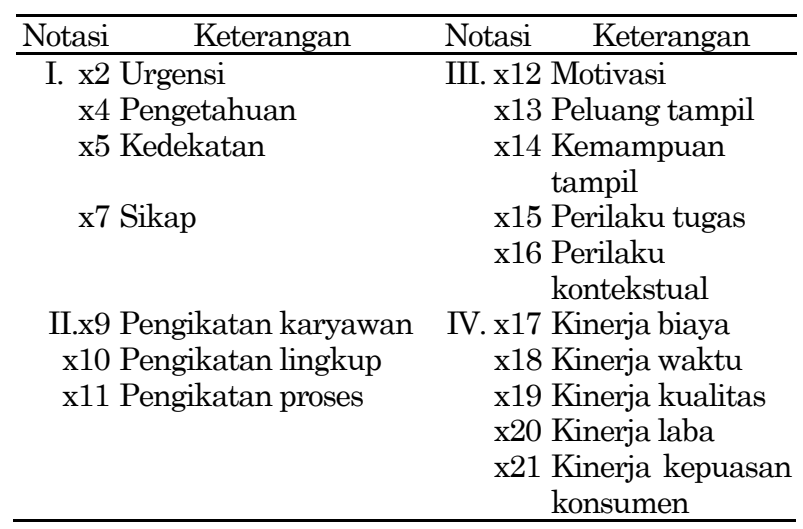

\section{Penelitian Utama}

Penelitian utama bertujuan untuk mengetahui tingkat skala kebaikan masing-masing variabel yang membentuk model berdasarkan penilaian pelaku jasa konstruksi dengan menggunakan 5 tingkat skala kebaikan (skala 1=sangat tidak baik dan skala 5 sangat baik). Penelitian utama dilakukan terhadap 204 responden yang terdiri dari 45 responden mewakili pemilik bangunan, 13 responden mewakili konsultan manajemen konstruksi, 30 responden mewakili konsultan perencana, 97 responden mewakili kontraktor, 19 responden mewakili subkontraktor/pemasok, Hasil penelitian utama yang prosesnya diawali dari konfirmatori faktor analisis, dan model persamaan struktural dapat dilihat pada Gambar 2.

Hasil analisis faktor konfirmatori menunjukkan kekuatan variabel indikator dalam merefleksikan variabel latennya. Gambar 2 (a) menunjukkan bahwa kedekatan pemangku kepentingan mempunyai pengaruh yang besar terhadap dampak pemangku kepentingan pada proyek konstruksi di Jawa Timur, disusul oleh sikap dari pemangku kepentingan dan pengetahuan yang dimiliki terkait dengan proyek. Hal ini sesuai dengan pendapat Walker dan Bourne [18] yang menyatakan bahwa kebutuhan terhadap keterlibatan atau kedekatan pemangku kepentingan dalam proyek merupakan kekuasaan dan kekuatan yang transparan dalam menentukan keberhasilan proyek. Makin dekat pemangku kepentingan dengan proyek, makin besar pengetahuannya tentang proyek. 


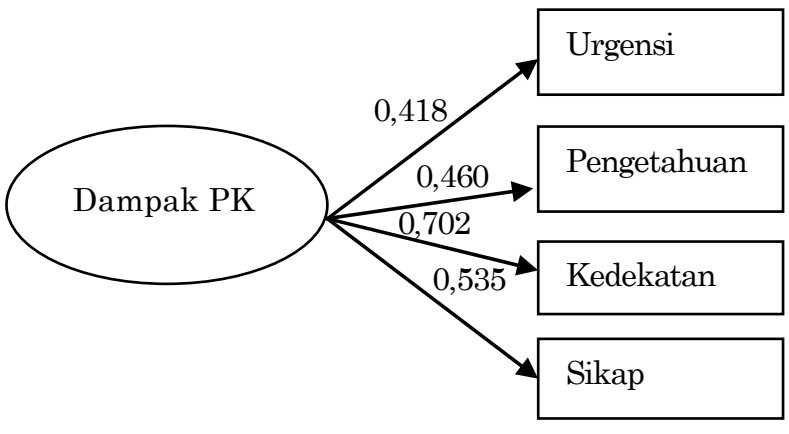

(a)

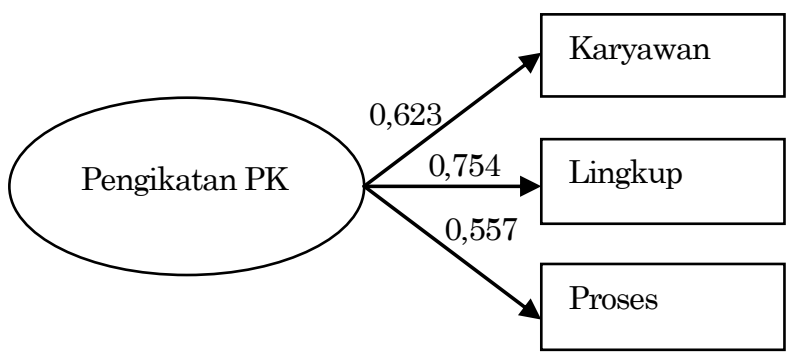

(b)

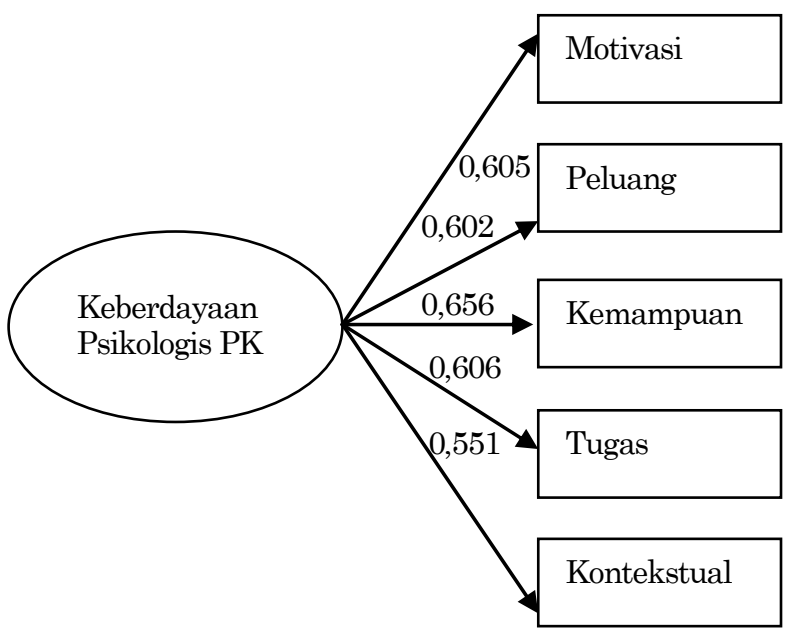

(c)

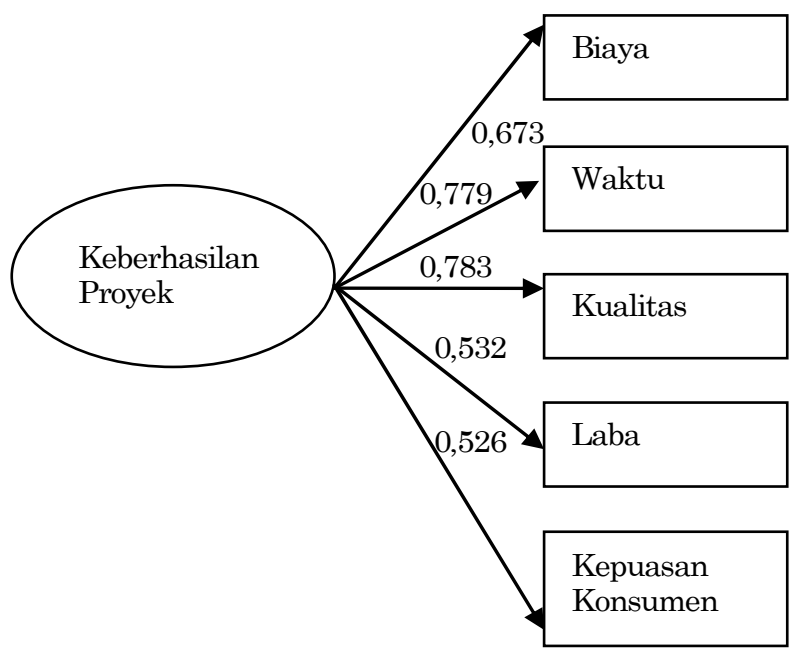

(d)

Gambar 2. Nilai koefisien Path konfirmatori faktor analisis
Gambar 2 (b) menunjukkan bahwa kemampuan perusahaan dalam meningkatkan lingkup pengikatan akan memberikan pengaruh yang signifikan terhadap pengikatan pemangku kepentingan, disusul oleh pengikatan karyawan. Temuan ini didukung oleh Ayuso et al.[5] yang menyatakan bahwa makin banyak lingkup pengikatan makin besar pula jumlah persetujuan kerjasama dengan perusahaan.

Gambar 2 (c) menunjukkan bahwa keberdayaan psikologis pemangku kepentingan lebih banyak direfleksikan oleh kemampuan tampil yang dilakukan manajemen terhadap pemangku kepentingan, yang disusul oleh perilaku tugas yang dihasilkannya. Hal ini sesuai dengan penelitian yang dilakukan Tuuli dan Rowlinson [16] yang menunjukkan bahwa kemampuan tampil mempunyai hubungan positif terhadap keberdayaan psikologis melalui perilaku tugas dan perilaku kontekstual.

Gambar 2 (d) memberikan informasi bahwa keberhasilan proyek lebih banyak direfleksikan oleh kinerja kualitas, yang disusul oleh kinerja biaya. Ini sesuai dengan pendapat Ling et al.[10] bahwa kualitas memegang peranan penting dalam menciptakan keberhasilan proyek, yang juga didukung oleh Toor dan Ogunlana [15] sebagai iron triangle dengan pengukuran kinerja biaya, waktu, dan kualitas. Kinerja kualitas sangat tergantung pada kualitas material, perencanaan kualitas konstruksi, teknologi, dan kelayakan ketrampilan pekerja. Kinerja biaya ditentukan oleh kecepatan pengambilan keputusan, hambatan waktu pelaksanaan, kecukupan waktu, dan kesenjangan waktu.

Persamaan model struktural penelitian utama seperti tertera pada Gambar 3. Nilai goodness of fit ditunjukkan dengan besarnya nilai chi-square $=315,541>168,813 ;$ probability $=0,00<0,05$; CMIN/DF $=2,720 ;$ TLI =0,674; CFI = 0,753; dan RMSEA $=0,089$. Nilai CMIN/DF dan RMSEA memenuhi batasan cut off value dan nilai TLI dan CFI dalam batas bisa diterima dalam skala nilai 0 sampai 1 (Hair et al.[8]). Dari hasil goodnes of fit dan estimasi parameter menunjukkan model yang fit. Artinya model yang dapat dengan baik mengukur kesesuaian input observasi atau sesungguhnya dengan prediksi dari model yang diajukan (Hair et al. [8]).

Dampak pemangku kepentingan mempunyai pengaruh yang signifikan terhadap keberhasilan proyek dengan koefisien path sebesar 0,416. Ini berarti pernyataan dalam hipotesis 1 adalah benar yang menunjukkan setiap kenaikan satu satuan dampak pemangku kepentingan akan memberikan kenaikan keberhasilan proyek sebesar 0,416 satuan. Pendapat ini didukung oleh Nguyen et al. [12]; dan 


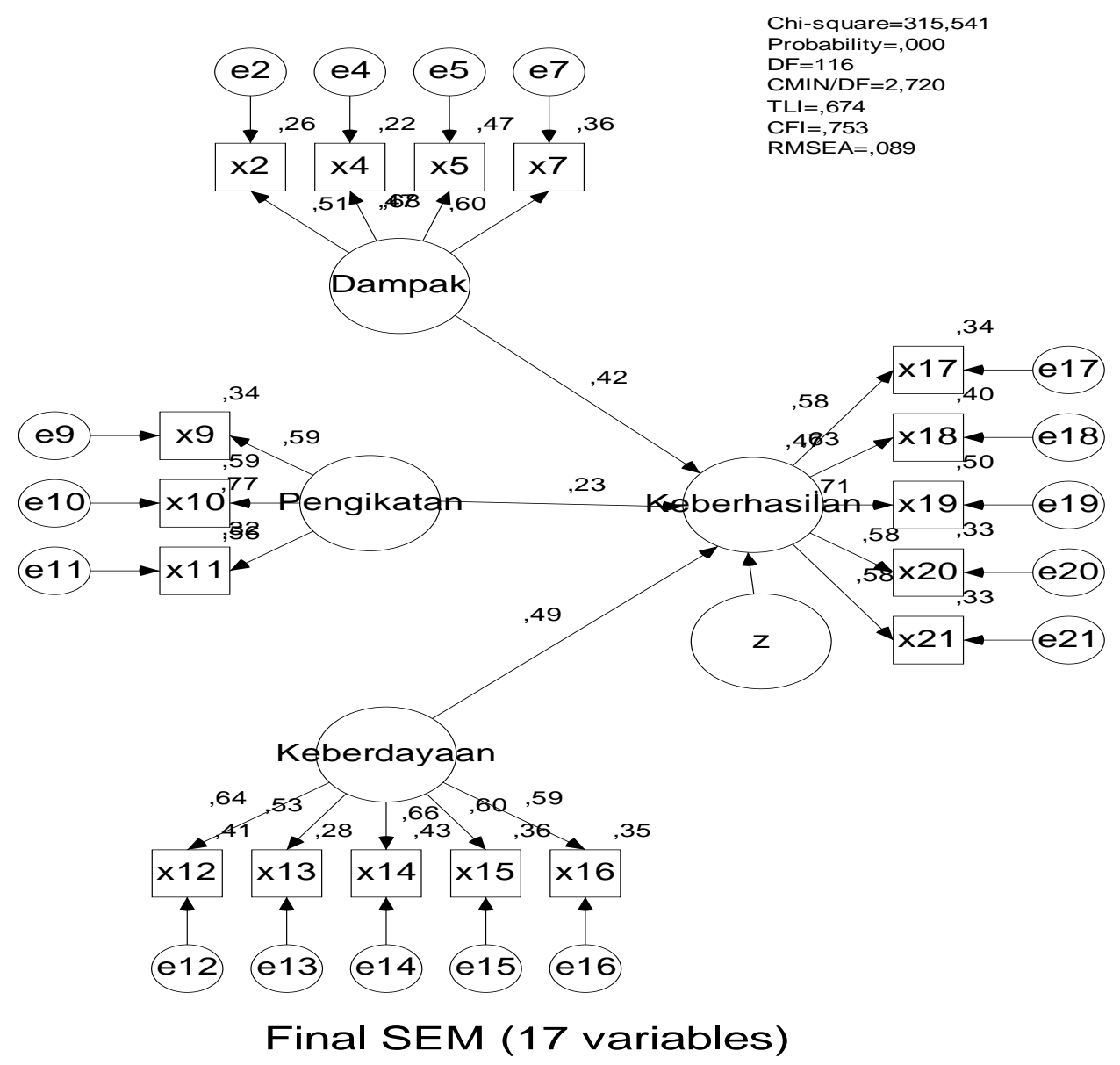

Gambar 3. Model Penelitian Utama

Tabel 2. Validasi penelitian

\begin{tabular}{|c|c|c|c|c|c|c|}
\hline \multirow[t]{2}{*}{ Kasus } & \multirow[t]{2}{*}{ Dampak } & \multirow{2}{*}{$\begin{array}{l}\text { Pengi- } \\
\text { katan }\end{array}$} & \multirow{2}{*}{$\begin{array}{l}\text { Keber- } \\
\text { dayaan }\end{array}$} & \multicolumn{2}{|c|}{$\begin{array}{l}\text { Keberhasilan } \\
\text { Proyek }\end{array}$} & \multirow{2}{*}{$\begin{array}{l}\text { Selisih } \\
-\quad \%\end{array}$} \\
\hline & & & & Aktual & Prediksi & \\
\hline DI & 3,75 & 3,33 & 4,00 & 4,20 & 4,30 & 2,38 \\
\hline TG & 4,00 & 3,67 & 4,40 & 4,60 & 4,68 & 1,74 \\
\hline WM & 4,25 & 4,00 & 4,60 & 4,80 & 4,96 & 3,33 \\
\hline AJP & 3,75 & 3,67 & 4,20 & 4,80 & 4,48 & 6,67 \\
\hline $\mathrm{TP}$ & 4,00 & 4,00 & 4,20 & 4,60 & 4,66 & 1,30 \\
\hline
\end{tabular}

Ward dan Chapman [17] yang membenarkan bahwa dampak dan ketidakpastian yang disebabkan pemangku kepentingan perlu diperhatikan dan dikelola oleh manajer proyek dalam mencapai keberhasilan proyek. Hal yang bisa dilakukan manajer proyek adalah lebih menekankan kedekatan pemangku kepentingan dengan proyek. Dengan demikian segala permasalahan di lapangan dapat diketahui dan segera dapat diselesaikan.

Pengikatan pemangku kepentingan mempunyai pengaruh yang kurang signifikan dalam keberhasilan proyek dengan koefisien path 0,233. Ini berarti bahwa pernyataan hipotesis 2 adalah benar tetapi nilai signifikansinya lebih rendah dari pada hipotesis 1. Hal ini menunjukkan bahwa setiap kenaikan satu satuan pengikatan pemangku kepen- tingan akan menambah kenaikan keberhasilan proyek sebesar 0,233 satuan.

Keberdayaan psikologis pemangku kepentingan mempunyai pengaruh yang paling signifikan dibandingkan 2 variabel laten lainnya dengan koefisien path 0,492. Ini berarti pernyataan dalam hipotesis 3 adalah benar yang menunjukkan setiap kenaikan satu satuan keberdayaan psikologis pemangku kepentingan akan memberikan kenaikan keberhasilan proyek sebesar 0,492 satuan. Hal ini sejalan dengan Tuuli dan Rowlinson [16] yang menyatakan bahwa keberdayaan membantu mengubah kondisi yang tidak mempunyai kekuatan menjadi lebih berdaya dengan meningkatkan perasaan karyawan secara mandiri dan jitu (Newstrom dan Davis [11]); dan menciptakan kemampuan tampil dengan melakukan pelatihan dan mengembangkan pengetahuan (Potdsakoff et al. dalam Tuuli dan Rowlinson [16]).

Model persamaan penelitian utama adalah:

Keberhasilan Proyek = 0,416 Dampak Pemangku

Kepentingan + 0,233 Pengikatan Pemangku Kepentingan + 0,492 Keberdayaan Psikologis Pemangku Kepentingan $+\xi$,

dimana $\xi$ adalah faktor galat yang diasumsikan berdistribusi normal. 


\section{Validasi Penelitian}

Validasi penelitian dilakukan pada lima buah perusahaan kontraktor yang berkedudukan di Surabaya yang sesuai dengan klasifikasi kontraktor yang diteliti dan terlibat sebagai responden dalam penelitian utama. Hasilnya adalah seperti pada Tabel 2.

Hasil validasi menunjukkan adanya kesamaan antara aktual dengan prediksi yang berada pada kisaran perbedaan rata-rata 3,08\% terhadap nilai aktual. Harapannya model ini dapat dipakai sebagai acuan yang bisa dipakai untuk alat prediksi keberhasilan proyek.

\section{Simpulan}

Keberdayaan psikologis pemangku kepentingan dan dampak pemangku kepentingan mempunyai pengaruh yang signifikan pada penelitian pendahuluan maupun penelitian utama. Pada penelitian utama, keberdayaan pemangku kepentingan terhadap keberhasilan proyek dengan koefisien path sebesar 0,492 menunjukkan bahwa variabel laten ini sangat signifikan terhadap keberhasilan proyek dengan lebih menekankan kemampuan tampil pemangku kepentingan Dampak pemangku kepentingan terhadap keberhasilan proyek dengan koefisien path 0,416 lebih mengutamakan kedekatan pemangku kepentingan dalam upaya memperoleh keberhasilan proyek yang diukur dari kinerja kualitas. Sebaliknya pengikatan pemangku kepentingan dengan koefisien path 0,233 menunjukkan hasil yang kurang signifikan dalam mencapai keberhasilan proyek. Validasi terhadap model tersebut mampu memprediksi keberhasilan proyek terhadap lima buah perusahaan kontraktor dengan rata-rata tingkat perbedaan antara kondisi aktual dan kondisi yang diprediksikan sebesar 3,08\%. Disarankan agar model tersebut dapat dikembangkan lagi untuk menggali lebih jauh pengaruh pengikatan pemangku kepentingan terhadap keberhasilan proyek, memperhatikan kedekatan pemangku kepentingan dalam proyek, dan memberikan kemampuan tampil pemangku kepentingan agar lebih baik dalam mencapai keberhasilan proyek. Untuk itu diperlukan penelitian lanjut agar model tersebut dapat lebih disempurnakan.

\section{Daftar Pustaka}

1. Aaltonen, K., Jaako, K., and Tuomas, O. Stakeholder Salience in Global Projects. International Journal of Project Management, 26, 2008, pp. 509-516.

2. Achterkamp, M. C., and Vos, Janita F. J., Investigating the Use of the Stakeholder Notion in Project Management Literature, a Meta Analysis.
International Journal of Project Management, 26, 2008, pp. 749-757.

3. Ahadzie, D. K., Proverbs, D. G., and Olomolaiye, P., Towards Developing Competency-Based Measures for Construction Project Managers: Should Contextual Behaviours be Distinguished from Task Behaviours? International Journal of Project Management, 26, 2008, pp. 631-645.

4. Atkin, B., and Skitmore. M., Editorial: Stakeholder Management in Construction. Journal of Construction Management and Economics. 26, 2008, pp. 549-552.

5. Ayuso, S., Rodriguez, M. A., Garcia, R., and Arino, M. A., Maximizing Stakeholders' Interest: An Empirical Analysis of the Stakeholder Approach to Corporate Governance. IESE Business School, University of Navara, 2006.

6. Chinyio, E. A., and Akintoye, A., Practical Approaches for Engaging Stakeholders; Finding from the UK. Construction Management and Economics, 26, 2008, pp. 591-599.

7. Cleland, D. I., and Ireland, L. R. Project Management: Strategic Design and Implementation, 5 th.edn. Mc Graw-Hill, New York, 2007.

8. Hair, J. F. H., Black, W. C., Babin, B. J., Anderson, R. E., and Tatham, R. L. Multivariate Data Analysis. Sixth Edition.Pearson Prentice Hall, New Jersey, 07458, 2006.

9. Lerbinger, O. Corporate Public Affair: Interacting with Interest Group, Media, and Government", Lawrence Eribaum Associates, London, 2006.

10. Ling, F. Y. Y, Low, S. P.,Wang, S. Q., and Lim, H. H., Key Project Management Practices Affecting Singaporean Firms' Project Performance in China. International Journal of Project Management, 27, 2009, pp. 59-71.

11. Newstrom, J. W., and Davis, K.. Organizational Behavior. Human Behavior at Work, Tenth Edition.Boston, McGraw Hill, 1997.

12. Nguyen, N. H., Skitmore, M., and Wong, J. K. W., Stakeholder Impact Analysis of Infrasrtucture Project Management in Developing Countries: A Study of Perception of Project Managers in State -Owned Engineering Firm in Vietnam. Construction Management and Economics, 27, 2009, pp.1129-1140.

13. Project Management Institute. A guide to the Project Management Body of Knowledge (PMBOK Guide), Fourth Edition, Project Management Institute, Newtown Square, PA., 2008.

14. Rowlinson, S., and Cheung, Y. K. F. Stakeholder Management Through Empowerment: Modeling Project Success. Construction Management and Economics, 26, 2008, pp. 611-623.

15. Toor, S. R., and Ogunlana, S. O., Beyond the' Iron Triangle': Stakeholder Perception of Key Performance Indicators (KPIs) for Large -Scale Public Sector Development Projects. International Journal of Project Management, 28, 2010, pp. 228-236. 
16. Tuuli, M. M., and Rowlinson, S., Empowerment in Project Teams: A Multilevel Examination of the Job Performance Implications. Journal of Construction Management and Economics, 27, 2009, pp. 473-498.

17. Ward, S. C., Chapman, C. B., and Curtis, B., On the Allocation of Risk in Construction Projects.
International Journal of Project Management. 9( 3), 1991, pp.140-147.

18. Walker, D. H. T., Bourne, L. M., and Shelley, A, Influence, Stakeholder Mapping and Visualisation. Journal of Construction Management and Economics, 26, 2008, pp. 645-658. 